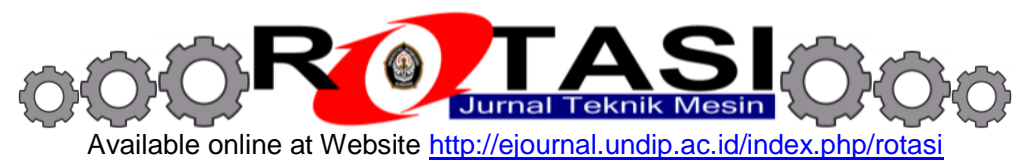

\title{
PERANCANGAN ABOVE KNEE PROSTHETIC UNTUK PASIEN AMPUTASI KAKI DI ATAS LUTUT
}

\author{
*Jamari, A.R. Ismawan \\ Laboratorium Perancangan Teknik dan Tribologi \\ Jurusan Teknik Mesin, Fakultas Teknik, Universitas Diponegoro \\ Jl. Prof. Soedarto SH, Tembalang, Semarang 50275 Indonesia, Telp/Fax: +62 247460059 \\ *E-mail: j.jamari@gmail.com
}

\begin{abstract}
ABSTRAK
Prostetis (prosthetic) merupakan perlengkapan artifisial yang menggantikan bagian tubuh yang hilang akibat trauma, penyakit, cacat bawaan, dan lain-lain. Kaki palsu atas lutut (above knee prosthetic) merupakan alat pengganti kaki untuk orang dengan amputasi kaki di atas lutut. Paper ini bertujuan untuk merancang sebuah kaki palsu atas lutut yang praktis, fleksibel, dan ergonomis, yang tidak terlalu mahal yang bekerja dengan prinsip-prinsip mekanika. Perancangan konsep produk menggunakan metode morfologi untuk menghasilkan alternatif-alternatif konsep. Dihasilkan lima buah konsep produk kaki palsu dengan spesifikasi yang berbeda-beda. Konsep produk terbaik ditentukan melalui matrik pengambilan keputusan.
\end{abstract}

Kata kunci: above knee prosthetic, kaki palsu, perancangan konsep, morfologi.

\section{PENDAHULUAN}

Prostetis merupakan perlengkapan artifisial yang menggantikan bagian tubuh yang hilang akibat trauma, penyakit, cacat bawaan, dan lain-lain. Perkembangan teknologi kesehatan untuk kaki palsu atas lutut atau above knee prosthetic sudah sangat maju terutama di negara Amerika, Jepang, Inggris, dan negara maju lainnya. Pada era globalisasi yang kompetitif ini industri di bidang teknologi kesehatan selalu dituntut untuk terus berinovasi mengembangkan teknologi yang tepat guna tanpa mengabaikan standar kualitasnya [1]. Kaki palsu atas lutut merupakan alat pengganti kaki untuk orang dengan amputasi kaki di atas lutut, yang penyebab utamanya antara lain karena penyakit diabetes [2], infeksi [3], dislokasi total knee arthroplasty yang berulang [4], dan lain-lain.

Produk kaki palsu yang ada di Indonesia masih didominasi oleh produk impor yang harganya cukup mahal. Industri pembuatan kaki palsu di Indonesia masih belum mampu memproduksi kaki palsu mekanis yang baik. Produk lokal yang ada kebanyakan berbahan serat fiber konvensional, lihat Gambar 1(a), yang kurang nyaman digunakan, lifetime pendek, tidak fleksibel, dan tidak ergonomis.

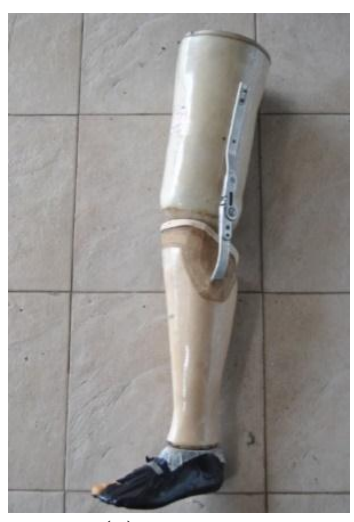

(a)

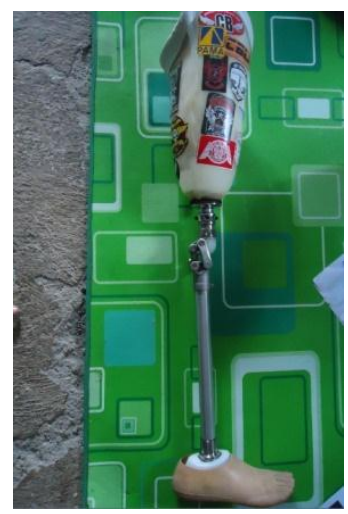

(b)

Gambar 1. Kaki palsu atas lutut (above knee prosthetic): (a) produk local dan (b) produk impor.

Fleksibilitas merupakan salah satu hal penting yang harus dimilki dari sebuah kaki palsu. Fleksibilitas yang dimaksud adalah kemampuan kaki palsu dalam melakukan fleksi dan ekstensi secara natural seperti pergerakan kaki manusia. Selain itu, pertimbangan secara ergonomis juga penting. Ergonomis di sini adalah kemampuan dalam menyesuaikan perbedaan ketinggian kaki pengguna, dan kemudahannya ketika diaplikasikan. Sebagai perbandingan, kaki palsu di negara maju sudah dilengkapi dengan sistem kontrol komputer dan shock hidrolis, dan sudah diseting untuk beberapa kondisi. Shock hidrolis digunakan agar kaki palsu dapat kembali dalam kondisi tegak (akibat gaya dorong yang dihasilkan pemampatan fluida) dan dapat berjalan secara natural, lihat Gambar 1(b). Sebelum digunakan, pemakai kaki palsu harus menyesuaikan dengan ukuran kakinya terlebih dahulu. Kemampuan untuk menyeting ketinggian kaki pasien ini tidak dimiliki oleh kaki palsu fiber yang banyak digunakan di Indonesia. Dari segi material 
yang digunakan, material kaki palsu yang dikembangkan di negara-negara maju menggunakan stainless steel, alumunium, titanium, fiber dan polyetilen.

Dari beberapa pertimbangan tersebut maka studi ini dilakukan untuk merancang sebuah kaki palsu atas lutut yang praktis, fleksibel dan ergonomis berbahan alumunium yang bekerja dengan prinsip-prinsip mekanika [5], dan tidak terlalu mahal. Diharapkan dapat memberikan sebuah langkah perubahan yang berharga bagi orang-orang dengan disabilitas di Indonesia.

\section{METODE PERANCANGAN}

Pada perancangan prostetik kaki palsu untuk pasien amputasi kaki atas lutut ini menggunakan metode perancangan morfologi $[6,7]$. Metode ini juga telah berhasil diterapkan dalam perancangan alat keramas portable untuk pasien rumah sakit oleh Jamari dan Yolanda [8]. Metode morfologi menggunakan struktur fungsi untuk menentukan alternatif-alternatif konsep produk. Kelebihan metode ini antara lain dapat menemukan banyak alternatif konsep produk, sistematik, dan menggunakan prosedur yang mudah diikuti.

Dari beberapa alternatif konsep produk yang dihasilkan, kemudian dipilih salah satu konsep terbaik sebagai konsep yang akan dibuat. Dalam memilih konsep produk yang terbaik digunakan metode matrik keputusan. Pada matrik ini setiap alternatif konsep produk diberi nilai. Metode ini terbukti dapat digunakan secara mudah dan efektif, terutama untuk evaluasi konsep produk yang belum dapat dibandingkan dengan persyaratan teknis secara langsung. Hal ini karena keduanya berada pada tingkat abstraksi yang berbeda. Konsep produk harus dievaluasi terhadap keinginankeinginan pengguna, yaitu tahap dimana persyaratan teknis belum tersusun. Pada tahap evaluasi setiap konsep produk dibandingkan dengan konsep produk lain, satu persatu secara berpasangan dalam hal kemampuan memenuhi keinginan pengguna. Kemudian memberi skor pada hasil perbandingan dan menjumlahkan skor yang diperoleh setiap konsep produk. Konsep produk dengan skor tertinggi adalah konsep yang terbaik.

\section{HASIL DAN PEMBAHASAN}

Gambar 2 hingga Gambar 6 menunjukkan hasil perancangan konsep produk untuk alternatif pertama hingga kelima. Pada konsep pertama seperti yang terlihat pada Gambar 2 ini bahan utamanya adalah aluminium. Material alumunium memiliki daya tahan terhadap korosi yang baik dan bobot yang ringan. Mekanisme kaki ini bekerja dengan memberikan dorongan pada lutut ketika paha berayun, kaki palsu mekanis ini dilengkapi peredam hidraulik yang berfungsi sebagai penahan dan memberikan gaya dorong ketika kaki melangkah fleksi dan ekstensi. Selain itu, pada konsep ini produknya adjustable, yaitu memiliki kemampuan dalam pengaturan ketinggian, yang bermanfaat dalam menyesuaikan ketinggian pengguna dan dapat dilimpahkan ke pengguna lain. Produk pada konsep ini juga fleksibel sehingga memberikan kenyamanan yang lebih. Kaki palsu ini dilengkapi dengan cover yang berfungsi sebagai pelindung komponen yang ada didalamnya dan juga berfungsi sebagai estetika yang menyerupai betis manusia.

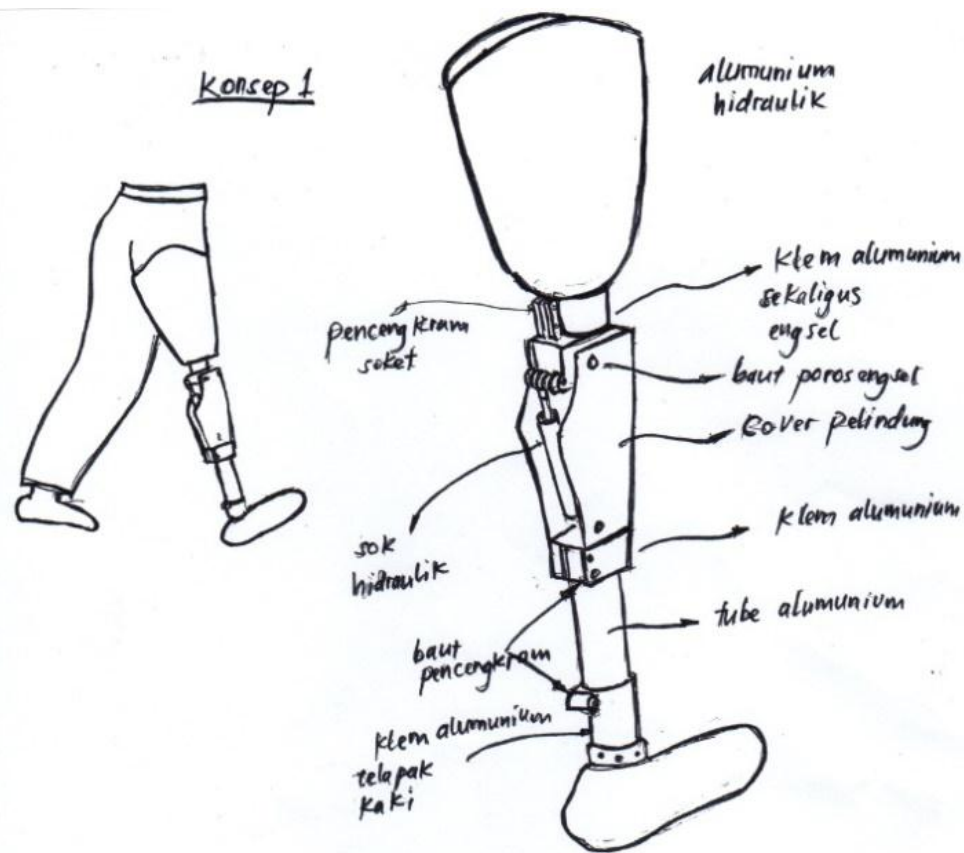

Gambar 2. Konsep produk pertama: above knee prosthetic alumunium dengan sok hidraulik.

Gambar 3 menunjukkan konsep produk kedua. Material pada konsep produk kedua ini berbahan polyetilen. Produk ini dirancang dengan desain engsel lutut yang sederhana, tanpa menggunakan pegas, memudahkan penggunanya dalam 
melakukan perawatan, dan kontrol berasal dari penggunanya sendiri dengan mengatur pola ayunan langkah kaki ketika berjalan. Polyetilen dipilih karena memiliki kekuatan cukup baik dan murah. Tabung polyetilen terdiri dari dua pipa yang memiliki diameter berbeda dan dilengkapi dengan lubang-lubang sebagai pengatur ketinggian untuk disesuaikan dengan tinggi pengguna.

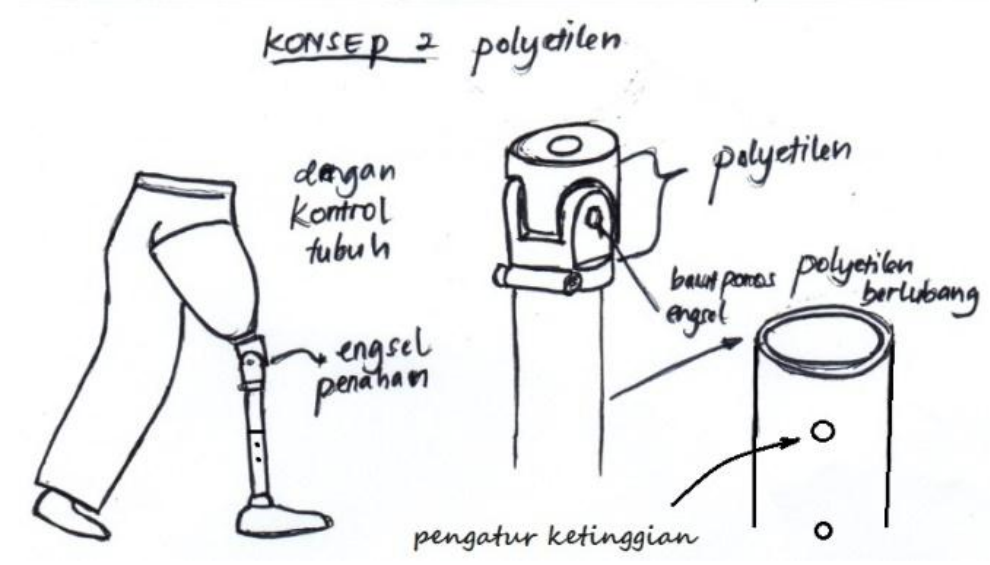

Gambar 3. Konsep produk kedua: above knee prosthetic berbahan polyetilen.

Konsep produk ketiga adalah seperti yang diperlihatkan pada Gambar 4. Desain konsep ketiga ini berbahan utama serat fiber, memliki bentuk estetika yang lebih menyerupai kaki. Hal ini tentunya dapat menimbulkan rasa percaya diri bagi pemakai kaki palsu ketika digunakan. Konsep ini dirancang berdasarkan ukuran tinggi kaki dari pengguna dan tidak dapat diubah-ubah. Selain itu juga memiliki desain engsel lutut yang sederhana, bekerja dengan kontrol tubuh melalui pengaturan pola ayunan kaki agar dapat menjaga stabilitas ketika berjalan.

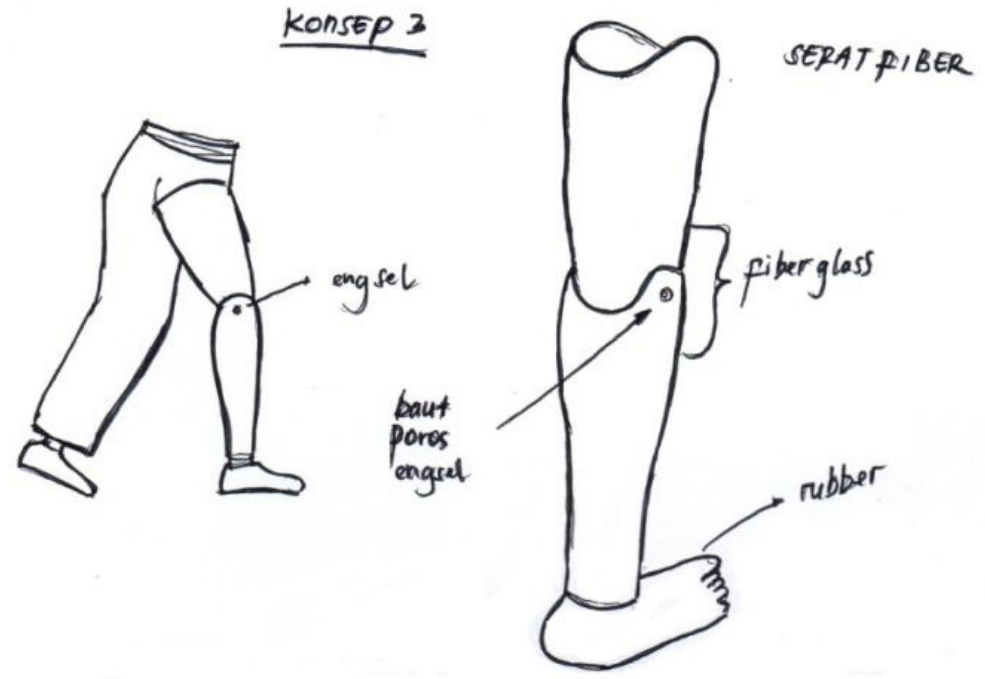

Gambar 4. Konsep produk ketiga: above knee prosthetic berbahan utama serat fiber.

Gambar 5 memperlihatkan alternatif konsep produk keempat. Pada konsep ini produk dirancang dengan desain gabungan mekanis dan elektrik. Bahan yang digunakan adalah alumunium dengan desain casing yang menyerupai betis manusia. Selain itu, dilengkapi dengan sok hidraulik elektrik dengan pengaturan microprocesor control agar pengguna dapat berjalan secara lebih alami dan nyaman seperti gerakan yang menyerupai gerakan kaki manusia. Sensor yang otomatis dapat membaca kondisi keadaan ketika berjalan, seperti sedang menaiki jalan berbukit atau sedang menuruni bukit. Microprocesor mengatur gerakan hidraulik, menyesuaikan gaya penahan yang disesuaikan dengan kondisi ketika berjalan demi meminimalkan energi ketika berjalan.

Konsep produk yang kelima ditampilkan pada Gambar 6. Pada perancangan konsep produk kaki palsu atas lutut kelima ini menggunakan bahan polimer yaitu polyetilen seperti perancangan konsep produk kedua. Produk ini dirancang dengan desain engsel lutut yang lebih sederhana menggunakan pegas. Kontrol berasal dari penggunanya sendiri, yaitu dengan mengatur pola ayunan langkah kaki ketika berjalan. Polyetilen dipilih karena memiliki kakuatan yang baik meskipun berbahan polimer, selain itu juga murah. Ketinggian kaki palsu dapat disesuaikan dengan tinggi pengguna. Tube polyetilen terdiri dari dua pipa yang memiliki diameter berbeda dan juga dilengkapi dengan lubanglubang sebagai pengatur ketinggian. 


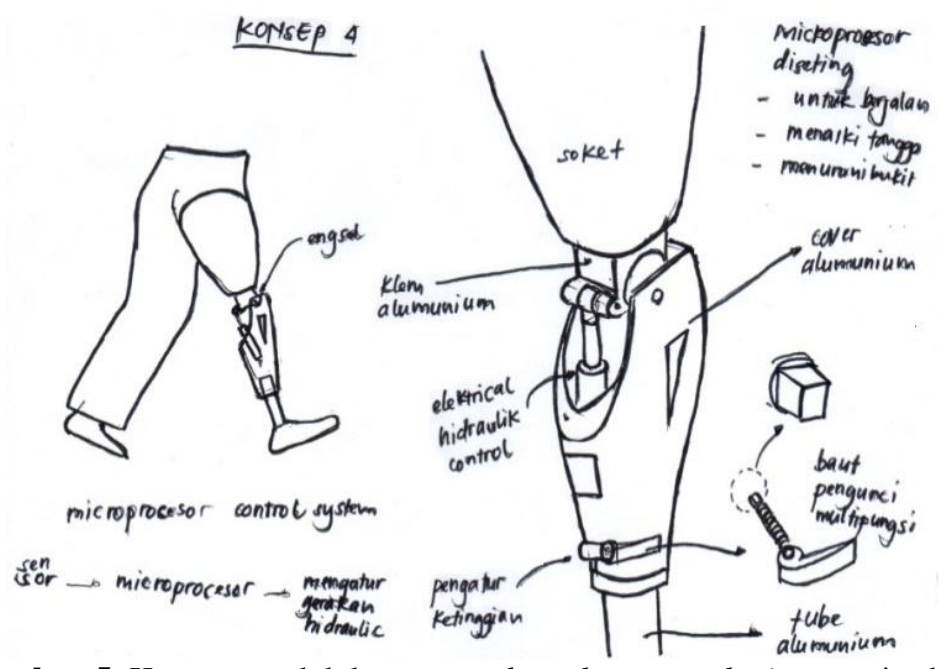

Gambar 5. Konsep produk keempat: above knee prosthetic seperti robot.

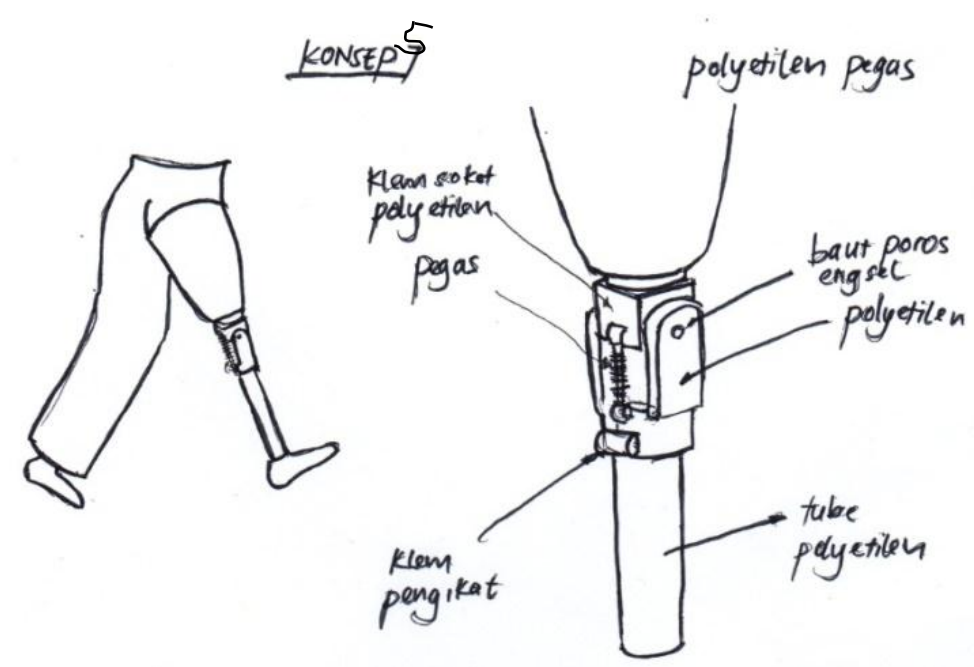

Gambar 6. Konsep produk kelima: above knee prosthetic berbahan polyetilen.

Dari kelima alternatif konsep prosuk yang telah dihasilkan, langkah selanjutnya adalah penentuan konsep produk terbaik. Tabel 1 menunjukkan hasil penilaian konsep produk menggunakan matrik pengambilan keputusan. Di sini nilai yang tertinggi adalah 10 dan yang terendah adalah 1 . Konsep produk yang dipilih adalah konsep produk yang memiliki nilai tertinggi. Dari table tersebut diperoleh bahwa nilai tertinggi adalah konsep produk pertama (K-1), sehingga konsep produk pertama dijadikan konsep terpilih.

Tabel 1. Matriks keputusan konsep produk kaki palsu atas lutut.

\begin{tabular}{llllllll}
\hline & & & \multicolumn{5}{c}{ Konsep } \\
\cline { 5 - 8 } No & \multicolumn{1}{c}{ Kriteria } & Wt & K-1 & K-2 & K-3 & K-4 & K-5 \\
\hline & & & & & & & \\
1. & Kuat & 10 & 10 & 7 & 7 & 10 & 7 \\
2. & Fleksibel & 9 & 9 & 7 & 7 & 9 & 8 \\
3. & Harga Murah & 9 & 8 & 9 & 9 & 6 & 9 \\
4. & Ringan & 8 & 7 & 8 & 7 & 7 & 8 \\
5. & Kemampuan setting ketinggian & 8 & 8 & 8 & 6 & 8 & 8 \\
6. & Mudah dirawat & 7 & 7 & 7 & 7 & 6 & 7 \\
7. & Umur tak hingga & 8 & 8 & 7 & 6 & 8 & 7 \\
8. & Pemasangan mudah & 7 & 7 & 7 & 7 & 5 & 7 \\
9. & Kemudahan pembuatan & 7 & 7 & 5 & 7 & 5 & 5 \\
10. & Komponen sedikit & 6 & 6 & 6 & 6 & 4 & 6 \\
& Jumlah & & $\mathbf{7 7}$ & $\mathbf{7 1}$ & $\mathbf{6 9}$ & $\mathbf{6 8}$ & $\mathbf{7 2}$ \\
\hline K & Konsep
\end{tabular}


Setelah pemilihan konsep produk dilakukan maka dilanjutkan dengan fase perancangan produk. Konsep produk yang masih berupa sketsa diberi bentuk atau diwujudkan menjadi sebuah kaki palsu atas lutut dengan bantuan software. Gambar 7 adalah hasil tiga dimensi perancangan above knee prosthetic yang terpilih berdasarkan beberapa alternatif konsep yang telah dibuat. Dari gambar ini maka didapatkan gambar teknik yang siap diberikan kepada bagian workshop untuk proses manufaktur.
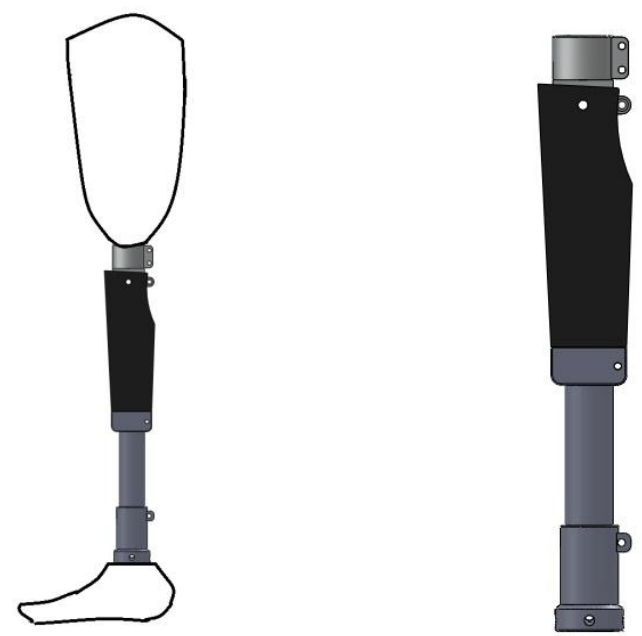

Gambar 7. Model keseluruhan kaki palsu atas lutut dari pengembangan konsep pertama (K-1).

\section{KESIMPULAN}

Prostetis merupakan perlengkapan artifisial untuk menggantikan bagian tubuh yang hilang akibat berbagai hal sehingga sangat bermanfaat bagi penggunanya. Perancangan prostetis kaki palsu atas lutut yang digunakan sebagai alat pengganti kaki untuk orang dengan amputasi kaki di atas lutut telah dilakukan menggunakan metode morfologi dan matrik pengambilan keputusan. Hasil perancangan konsep produk dengan beberapa keunggulan seperti fleksibel, ergonomis dan relatif murah telah dihasilkan. Diharapkan penemuan ini menjadi starting point dalam pengembangan alat-alat kesehatan lokal di Indonesia demi kemandirian bangsa.

\section{DAFTAR PUSTAKA}

[1] Raschke, S.U., Orendurff, M.S., Mattie, J.L., Kenyon, D.E.A., Jones, O.Y., Moe, D., Winder, L., Wong, A.S., Moreno-Hernandez, A., Highsmith, M.J., Sanderson, D.J., Kobayashi, T., 2015, "Biomechanical characteristics, patient preference and activity level with different prosthetic feet: A randomized double blind trial with laboratory and community testing," Journal of Biomechanics, 48, pp. 146-152.

[2] Vitriana, 2002, 'Rehabilitasi pasien amputasi bawah lutut dengan menggunakan immediate post operative prosthetic," Report, Bagian Ilmu Kedokteran Fisik dan Rehabilitasi, Universitas Padjadjaran, Bandung.

[3] Fedorka, C.J., Chen, A.F., McGarry, W.M., Parvizi, J., Klatt, B.A., 2011, "Functional ability after above-the-knee amputation for infected total knee arthroplasty," Clinical Orthopaedics and Related Research, 469, pp. 1024-1032.

[4] Pao, J.L., Jiang, C.C., 2003, “Above-knee amputation after recurrent dislocations of total knee arthroplasty," The Journal of Arthroplasty, 18 (1), pp. 105-109.

[5] Wentink, E.C., Koopman, H.F.J.M., Stramigioli, S., Rietman, J.S., Veltink, P.H., 2013, "Variable stiffness actuated prosthetic knee to restore knee buckling during stance: A modeling study," Medical Engineering \& Physics, 35, pp. 838-845.

[6] Pahl, G., and Beitz, W., 1996, Engineering Design, A Systematic Approach, Springer-Verlag, Inc., London.

[7] Ismawan, A.R., 2013, Perancangan dan Analisa Above Knee Prosthetic untuk Pasien Amputasi Kaki di Atas Lutut Dengan Desain Fleksibel dan Ergonomis, Tugas Akhir, Universitas Diponegoro, Semarang, Indonesia.

[8] Jamari, Yolanda, A.V., 2014, "Perancangan dan pembuatan alat keramas portable untuk pasien rumah sakit dengan metode morfologi," J@TI Undip, IX(2), pp. 105-108. 